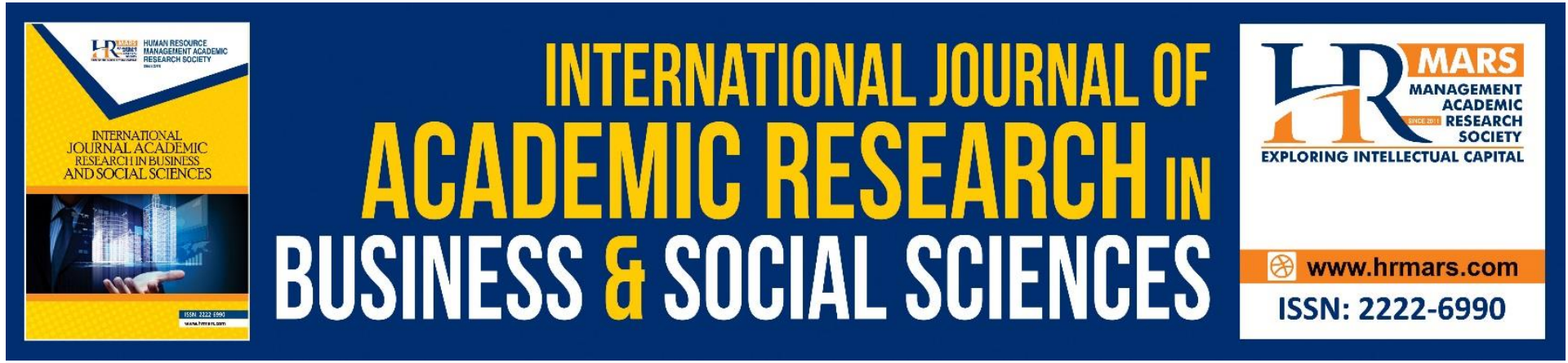

\title{
Learning English Online: The Questions of Skill, Will, Self- Regulation and Academic Performance
}

Kamisah Ariffin, Norizul Azida Darus \& Norhajawati Abdul Halim

To Link this Article: http://dx.doi.org/10.6007/IJARBSS/v11-i6/10159

DOI:10.6007/IJARBSS/v11-i6/10159

Received: 16 April 2021, Revised: 19 May 2021, Accepted: 30 May 2021

Published Online: 28 June 2021

In-Text Citation: (Ariffin et al., 2021)

To Cite this Article: Ariffin, K., Darus, N. A., \& Halim, N. A. (2021). Learning English Online: The Questions of Skill, Will, Self-Regulation and Academic Performance. International Journal of Academic Research in Business and Social Sciences, 11(6), 1716-1727.

Copyright: (c) 2021 The Author(s)

Published by Human Resource Management Academic Research Society (www.hrmars.com)

This article is published under the Creative Commons Attribution (CC BY 4.0) license. Anyone may reproduce, distribute, translate and create derivative works of this article (for both commercial and non-commercial purposes), subject to full attribution to the original publication and authors. The full terms of this license may be seen at: http://creativecommons.org/licences/by/4.0/legalcode

Vol. 11, No. 6, 2021, Pg. 1716 - 1727

http://hrmars.com/index.php/pages/detail/IJARBSS

JOURNAL HOMEPAGE

Full Terms \& Conditions of access and use can be found at http://hrmars.com/index.php/pages/detail/publication-ethics 


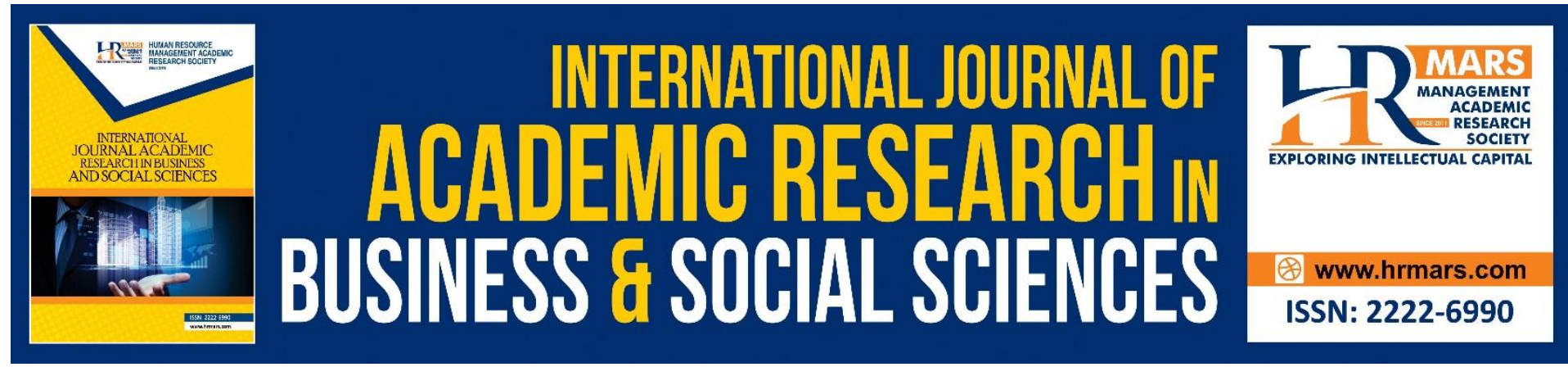

\title{
Learning English Online: The Questions of Skill, Will, Self-Regulation and Academic Performance
}

\author{
Kamisah Ariffin ${ }^{1}$, Norizul Azida Darus² \& Norhajawati \\ Abdul Halim ${ }^{3}$
}

${ }^{1}$ Academy of Language Studies, Universiti Teknologi MARA Pahang, 26400 Bandar Tun Abdul Razak Jengka, Pahang, Malaysia, ${ }^{2,3}$ Academy of Language Studies, Universiti Teknologi MARA

Perlis, 02600 Arau, Perlis, Malaysia.

Email:kamisah@uitm.edu.my_norizulazida@uitm.edu.my,norhajawati@uitm.edu.my

\begin{abstract}
Students' learning strategy is essential to ensure how students are able to manage their studies. Unlike traditional classroom where regular class meetings and instructors monitoring and supporting students' learning, online learning requires students' own skills, motivation, and self-regulation. This study aimed at identifying students' learning strategy in learning English online. This was measured using the Learning and Study Strategies Inventory (LASSI) that examined students' strategy use under the dimensions of skill, will and self-regulation. The data were procured from a set of questionnaires constructed based on LASSI components and distributed to 127 diploma level students, registered in an English course in a university in Malaysia. The analysis shows that the students employed all the strategies examined in their learning, indicating that they had the skills and ability related to identifying and acquiring information, and demonstrating their knowledge on evaluative procedure at varying levels. However, the analysis points out that not all the subscales can be a predictor for the students' performance. There were varying correlations between students' strategic learning and their academic performance. The findings also indicate that gender influenced the use of the strategic learning components, that female students had better control when dealing with motivation, emotion and management of a person's own cognition, behaviour and emotion, while male students were better in the aspects of knowledge and the application of use. The findings can inform instructors or institutions on providing academic resources or any specific intervention programme that can be organised to ameliorate students' academic performance.
\end{abstract}

Keywords: Learning Strategies, Attitude, Self-Regulation, Academic Performance

\section{Introduction}

Language learning strategies are mindful feelings and behaviours that learners use and adapt to help them improve their knowledge and understanding of the target language. They are used to enable learning tasks and to engrave the language learning progress and development (Cohen, Weaver \& Yuan-Tao, 1996). Language learning strategies have been one of the most-researched areas in the second language learning over the past 30 years. It 
is found that the language learning strategies adopted by a learner that can best assist their learning may be determined by several factors. These include the learning context that is formed by the educational and cultural ethics of the society in which the learner is studying the language, learner's goals and purpose, learners' attitude and motivation and learner's learning styles and preferences. Thus, as claimed by Oxford (1998, p. 237), the strategies adopted by the learners may reflect 'personal preference rather than innate endowment'. Learners need to be made aware of the strategies that they use in their language learning as it can help them achieve greater control of their own learning. As reiterated by Oxford (1990), students have the advantages in learning by using the strategy when they know the particular strategies which are essential to them, and they are able to use them. They would adapt the strategies and transmit them into more innovative situation.

Research that measures learners' strategic learning in learning a foreign language and its effectiveness has been replete, however, it is by no means exhaustive. Empirical studies have looked into learners' learning strategies using under the taxonomies of: direct learning strategies and indirect learning strategies (Rubin 1981), social strategies and cognitive strategies (Fillmore, 1979), good language learners' strategies (Naiman et al., 1978), learners' behaviour (Politzer and Groarty, 1985), metacognitive strategies, cognitive strategies, and social strategies (O'Malley and Chamot, 1990), cognitive strategies, memory, compensation, metacognitive strategies, affective strategies, and social strategies (Oxford, 1990), cognitive strategies and self-management strategies (Wenden, 1991), and executive skills and nonexecutive skills (Sternberg, 1983). In general, these studies have shown learners' strategies in acquiring a foreign language and its correlation with performance in that language.

The COVID19 pandemic has promoted the online platform as a new normal in the education process. Since online learning is learner-centred (Clarke and Hermens, 2001), learners need to control their own learning. Learners are required to learn independently to suit their own learning style and preference. Independent learning requires skills, motivation and selfregulation. The current situation, of which online learning has somehow forced independent learning among the students, has motivated this investigation into the students' strategic learning.

Although the Strategy Inventory for Language Learning (SILL) (Oxford, 1995) has been utilized to explore the learning strategies used by foreign language learners, this present study chooses to adapt the Learning and Study Strategies Inventory (LASSI) developed by Weinstein, Schulte and Palmer (1987) to discover the learners' strategies in learning English online and its association with their academic performance in that course. This is because the researchers feel that LASSI is able to assess both the learners' thought, processes and behaviours during learning. Furthermore, in online learning, students are confronted with challenges that require cognitive and metacognitive skills to deal with the language lessons. Thus, the inventory would be able to measure learners' use of learning and study strategies as it covers the three important components to successful learning: skill, will and selfregulation.

\section{Learning and Study Strategies Inventory (LASSI)}

The Learning and Study Strategies Inventory (LASSI) was developed by Weinsten, Schulte and Palmer (1987) to measure students' use of learning and study strategies. This self-reported 
questionnaire contains ten scales that assess students' use of learning and study strategies which are: anxiety, attitude, concentration, information processing, motivation, selecting main ideas, self-testing, test strategies, time management and using academic resources. These 10 scales are related to three components of strategic learning: skill, will and selfregulation.

The skill component of the LASSI scales examine learners' strategies, skills and thought processes that are related to identifying, acquiring and constructing meaning for new information, ideas and procedures. It also looks into how learners formulate and establish the new knowledge attained for tests or assessments. The will component of the scales measure learners' attitudes and their awareness in learning, diligence and self-discipline, and also their preparedness to put in effort to complete academic requirements effectively. This component also includes the degree of learners' anxiety with regards to their academic achievement. The self-regulation component, on the other hand, measures how learners manage or selfregulate their learning progression through the use of time efficiently, concentrating their attention on learning and the learning demands for a class, and using study supports. Table 1 below summarizes the LASSI components, subscales and sample items for each. 
Table 1: Learning and Study Strategies Inventory (LASSI)

\begin{tabular}{|c|c|c|}
\hline COMPONENT & SUBSCALE & Sample Item \\
\hline \multirow{3}{*}{ SKILL } & $\begin{array}{l}\text { Information } \\
\text { Processing (IP) }\end{array}$ & $\begin{array}{l}\text { To help me remember new principles we are } \\
\text { learning in class, I practice applying them. } \\
\text { I try to find relationships between what I am } \\
\text { learning and what I already know. }\end{array}$ \\
\hline & $\begin{array}{l}\text { Selecting Main Ideas } \\
\text { (SMI) }\end{array}$ & $\begin{array}{l}\text { I have difficulty identifying the important points } \\
\text { in my reading. } \\
\text { When studying, I seem to get lost in the details } \\
\text { and miss the important information. }\end{array}$ \\
\hline & Test Strategies (TS) & $\begin{array}{l}\text { I have difficulty adapting my studying to different } \\
\text { types of courses. } \\
\text { I have trouble understanding just what a test } \\
\text { question is asking. }\end{array}$ \\
\hline \multirow{3}{*}{ WILL } & Anxiety (ANX) & $\begin{array}{l}\text { When I am studying, worrying about doing } \\
\text { poorly in a course interferes with my } \\
\text { concentration. } \\
\text { I feel very panicky when I take an important test. }\end{array}$ \\
\hline & Attitude (ATT) & $\begin{array}{l}\text { I feel confused and undecided as to what my } \\
\text { study goals should be. } \\
\text { I only study the subjects I like. }\end{array}$ \\
\hline & Motivation (MOT) & $\begin{array}{l}\text { When work is difficult I either give up or study } \\
\text { only the easy parts. } \\
\text { I set goals for the grades I want to get in my } \\
\text { classes. }\end{array}$ \\
\hline \multirow{4}{*}{$\begin{array}{l}\text { SELF- } \\
\text { REGULATION }\end{array}$} & Concentration (CON) & $\begin{array}{l}\text { My mind wanders a lot when I study. } \\
\text { If I get distracted during class, I am able to } \\
\text { refocus my attention. }\end{array}$ \\
\hline & Self-Testing (ST) & $\begin{array}{l}\text { I check to see if I understand what the instructor } \\
\text { is saying during class. } \\
\text { To check my understanding of the material in a } \\
\text { course, I make up possible test questions and try } \\
\text { to answer them. }\end{array}$ \\
\hline & $\begin{array}{l}\text { Time Management } \\
\text { (TM) }\end{array}$ & $\begin{array}{l}\text { I find it hard to stick to a study schedule. } \\
\text { When I decide to study, I set aside specific length } \\
\text { of time and stick to it. }\end{array}$ \\
\hline & $\begin{array}{l}\text { Using } \quad \text { Academic } \\
\text { Resources (UAR) }\end{array}$ & $\begin{array}{l}\text { I compare class notes with other students to } \\
\text { make sure my notes are complete. } \\
\text { I use special study helps such as italics and } \\
\text { headings, that are in my book. }\end{array}$ \\
\hline
\end{tabular}

The LASSI scales measure both the covert and overt thoughts and behaviours of the learners which connect to effective learning (Weinstein, 1987). In addition, it can be used as a diagnostic and prescriptive measure for any remedial or intervention programs. Studies have shown that there is a correlation between LASSI subscales and academic performance, and the influence of gender in the usage of learning approaches. 


\section{The Study}

This study employed the LASSI scales to measure the levels of students' strategies in learning English online under the components of skill, will and self-regulation. Specifically, it seeks to answer the following the research questions:

1. Which LASSI subscales are frequently used by the students in learning English online and what is the level of use of each subscale?

2. Which strategic learning component is the predictor of the learners' performance in the English course?

3. Does gender influence the students' learning and study strategies?

One hundred diploma level students (53 males and 74 females) from a public university took part in this study. They were chosen as they fulfill the criteria needed for the study: i) students enrolled in an English course, ii) students who had experienced learning the English course through online learning, and iii) students who were available and willing to take part in the study.

The adapted version of the LASSI was used to examine the learners' strategy use. The $3^{\text {rd }}$ Edition of LASSI contains 60 items that assess students' general learning strategies. However, in this study, the researchers decided only to include 55 items that can be related to the English course per se. In addition, general terms such as 'attending school' and 'subjects' were changed to 'attending classes' and 'topics' to relate to attending English classes and topics in English.

The questionnaire was divided into 4 parts. Part A included both open-ended and close-ended questions to elicit information on the participants' demographic background and their achievement in the English course. Parts B, C, and D contained 55 statements from LASSI that gauged students' strategy use in the strategic learning components of skill, will and selfregulation respectively. Five-point Lickert scale of 1 (not at all typical of me) to 5 (very much typical of me) was used for each statement. Participation to the study was invited through message blast to the students using the whatsapp application. Only those who accepted the invitation were provided with the link to the questionnaire. 133 questionnaires were received but only 127 had complete answers.

Only completed questionnaires were analysed. The data were measured quantitatively, involving frequency counts of the items in the LASSI inventory. Statistical calculation of interval was used to evaluate the level of strategies used by the students. Table 2 below shows classification of the strategy level based on the mean score.

Table 2: Mean Score and Categories of Strategy Level

\begin{tabular}{cl}
\hline Total Mean Score & Categories of Level Use \\
\hline $1.00-1.79$ & Very Low \\
$1.80-2.59$ & Low \\
$2.60-3.39$ & Moderate \\
$3.40-4.19$ & High \\
$4.20-5.00$ & Very High \\
\hline
\end{tabular}


Pearson correlation coefficient analysis was made to regulate the correlation between the students' strategy use and their achievement in the English course. In addition, the one-way ANOVA test was also conducted to find the association between the gender variable and the learning strategies domains.

\section{Findings and Discussion}

The online learning requires skills, motivation, and self-regulation. This study has looked into the students' study and learning strategies in learning English online. In general, it is found that the students employed all the strategies examined, indicating that they had the skill and ability related to identifying and acquiring information as well demonstrating their knowledge on evaluative procedure. In addition, the students were receptive to learning and willing to exert their effort to complete academic requirements in the online environment. This was reflected in their attitude, interest and worries about their academic performance. The analysis also shows that students manage and self-regulate their learning process by focusing attention on the learning requirements such as assignments and tests, and utilizing the study supports provided by instructors such as extra class sessions, group discussions and learning materials provided.

\section{Use of LASSI Subscales in Learning English Online}

The findings indicate that, in general, the students' skill, will and self-regulation in learning English are at the medium level. However, there is a small difference in the mean scores among the components. The total mean score for the skill component was 3.242, while the scores for will and self-regulation were 3.146 and 3.149 respectively. This indicates that all the strategies were well-employed by the students in their online learning.

Table 3 below shows the detailed mean scores and the level of use of the 10 subscales under each of these components.

Table 3: Use of LASSI subscales in Online English Learning

\begin{tabular}{lllll}
\hline \multirow{5}{*}{ SKILL } & Subscales & \multicolumn{2}{l}{$\begin{array}{l}\text { N=100 } \\
\text { Missing=0 }\end{array}$} & \\
\cline { 2 - 5 } & & $M$ & $S D$ & Level of Use \\
\hline \multirow{3}{*}{ WILL } & IP & 3.663 & .564 & High \\
& SMI & 3.262 & .424 & Medium \\
& TS & 2.800 & .699 & Medium \\
\cline { 2 - 5 } & & 3.242 & .562 & Medium \\
\hline \multirow{3}{*}{ SELF- } & ATT & 2.572 & .662 & Low \\
REGULATION & MOT & 3.435 & .554 & High \\
& ANX & 3.430 & .615 & High \\
\cline { 2 - 5 } & & 3.146 & .610 & Medium \\
& TM & 2.970 & .542 & Medium \\
& ST & 2.978 & .709 & Medium \\
& UAR & 3.344 & .635 & Medium \\
\cline { 2 - 5 } & & 3.304 & .757 & Medium \\
\hline
\end{tabular}


As can be seen from the table, the students showed strengths in the subscales of Information Processing (IP) (mean=3.663), Motivation (MOT) and Anxiety (ANX) (mean=3.435, and mean $=3.430$ respectively). As these students had gone through two semesters of the study programme online, they were somewhat familiar with the learning process. In addition, the university provides support on study skills for all students as a bridging course prior to entering the main study programme. Among the skills provided include identifying information and information processing. Although the subscale of Selecting Main Idea (SMI) scored medium (mean=3.262), the difference is not too significant compared to IP. This is because the students used the skill of selecting main ideas when processing the information. Thus, the students had ample experience and skills in information processing, hence, the highlevel score in this subscale.

Although Attitude (ATT) scored low (mean=2.572) indicating low interest and general attention, their motivation and anxiety, the students were, however, able to overcome such weakness. Malaysians, like any other East Asians, are highly competitive when it comes to education and examinations. Although the students in this study might have low attitude towards learning, they still consider high examination results and education achievement as important determinants of a one's progress to higher education, as well as occupational opportunities. Thus, the low score in the ATT subscale was countered by the high scores in MOT and ANX. The students realised that the goal of university education is to do well, if not excel.

Other subscales received medium level of scores and did not yield significant differences between them. This shows that the students' low attitude towards learning is not a predictor or key factor driving their motivation and anxiety in learning. This in line with previous studies which looked into the relationship between students' attitude and learning outcomes (Khalil, Williams and Hawkins, 2018; West et al., 2016). In addition, the analysis reported that the Self-Testing (ST) and Using Academic Resources (UAR) subscales did not have significant differences (mean=3.344, and mean=3.304 respectively). This may be due to the good support services provided by the university. Support through library services such as learning resources is made available to facilitate online and distance learning. In addition, a system that gathered past examination papers was also made available online to enable students to do self-testing at their own convenient time. Webinars and briefings were often held by the librarians to guide students on the use of these support services. Along the same line, the academic administration also ensures that standardised academic resources are provided to the students. Sachs et al (2019) found similar findings that the development of Student Academic Support Services department in the University of Texas Southwestern Medical Center that standardizes academic resources utilization among the students might explain the lack of variation among the LASSI subscales of ATT and UAR.

Nevertheless, although there was lack of significant difference among the medium level subscales, there was still a marginal difference in the Time Management (TM) and Concentration (CON) (mean=2.970, and mean=2.978 respectively). With online and distance learning, it seems that students faced slight challenges in managing time and concentrating on their studies, unlike the traditional, face-to-face learning where almost everything was on schedule and monitored by the instructors. Although the score difference is marginal, this may call for interventions advocating for time management and further expansion for more 
reliable study plans. Haghania and Sadeghizadeh (2011), McConville, McAleer and Hahne, (2017), and Sera and McPherson (2019) reported some intervention programmes targeting these LASSI subscales to improve students' performance. These include having students attending workshops on time management, overall wellness, testing strategies and developing study plans.

\section{The Relationship between the Strategic Components Use and Performance}

Identifying the relationships between academic performance and learning strategies is useful because it can provide students and instructors with information regarding to strengths and weaknesses that can be applied to help students' in their learning. This study is interested in the direct contribution of the LASSI subscales to academic performance in online learning.

The analysis shows that not all the subscales can be predictor for the students' performance or achievement. Table 4 below illustrates the relationship of the 10 subscales and the students' performance in their English course.

Table 4: The correlations for 10 LASSI subscales and performance

\begin{tabular}{llll}
\hline Component & Subscales & Results & p-Value \\
\hline \multirow{3}{*}{ SKILL } & IP & $-.236^{* *}$ & .009 \\
& SMI & $-.190^{*}$ & .029 \\
& TS & .119 & .118 \\
\hline \multirow{3}{*}{ WILL } & ATT & $.310^{* *}$ & .001 \\
& MOT & -.017 & .434 \\
\multirow{3}{*}{ SELF-REGULATION } & ANX & .045 & .327 \\
& TM & $.230^{*}$ & .011 \\
& ST & $.216^{*}$ & .015 \\
& UAR & -.017 & .431 \\
& TON & $-.173^{*}$ & .043 \\
\hline
\end{tabular}

**Correlation is significant at the 0.01 level (1-tailed)

* Correlation is significant at the 0.05 level (1-tailed)

The data shows that five of the subscales had positive relationship with the students' performance in their English course. These were TS ( $r=.119)$, ATT $(r=.310, p<0.01)$, ANX $(r=.045), \operatorname{TM}(r=.230, p<0.05)$, and CON $(r=.216, p<0.05)$. On the other hand, other subscales, namely, IP, SMI, MOT, ST and UAR had negative relationship with the students' performance $(r=-.236(p<0.01),-.190(p<0.05),-.017,-.017$, and $-.173(p<0.05)$ respectively). Many studies employing LASSI to identify the relationship between learning strategies and academic performance have shown different subscales as predictors to students' performance. For example, Schutz, Leane Dalton and Tepe (2013) examined the connection between chiropractic students' learning and study strategies and general examination performance. They found that learning and study strategies were predictive of examination performance in chiropractic students, and four LASSI subscales, i.e ANX, CON, SMI and TS were significant predictors of their scores. Along the same line, Alkhateeb and Nasser (2014) assessed the learning and study strategies of university students in Qatar and their academic achievement. They found that all the subscales, except UAR were significantly correlated with the students' GPA. Among the subscales, ANX and TS were significant predictors of the students' academic achievement. In another study, Khalil, William and Hawkins (2017) identified significant 
associations between ANX, IP, MOT, SMI and TS and students' performance in the anatomical sciences and United States Medical Licensing Examination ${ }^{\circledR}$ (USMLE ${ }^{\circledR}$ ) Step 1 examinations.

Although the subscales predicting the academic achievements in the present study and the literature vary, however, the findings have shown that students' strategic learning involving skill, will and self-regulation do play a part in students' academic achievement. It seems that which subscales were more significant predictors to performance depended largely on the nature of the course take. What is more important is the implication of the findings. Identifying students who lack these strategic skills may facilitate any intervention programmes that can maximise their academic achievement.

\section{The Used of Learning Strategies Domains and Gender}

The analysis indicates that there are differences in the use of strategic domains between male and female students in their online learning.

Table 5: Gender and the Learning Strategies Domains Used

\begin{tabular}{lllll}
\hline \multirow{2}{*}{ Gender } & \multicolumn{2}{l}{$\begin{array}{l}\text { N=100 } \\
\text { Missing=0 }\end{array}$} \\
\cline { 2 - 5 } & & $M$ & $S D$ & Level of Use \\
\hline \multirow{3}{*}{ SKILL } & $\mathrm{M}$ & 3.622 & .564 & High \\
\cline { 2 - 5 } WILL & $\mathrm{F}$ & 3.322 & .424 & Medium \\
\hline SELF- & $\mathrm{M}$ & 2.591 & .662 & Low \\
REGULATION & $\mathrm{F}$ & 3.391 & .554 & Medium \\
\cline { 2 - 5 } & $\mathrm{M}$ & 2.721 & .542 & Medium \\
\hline
\end{tabular}

As shown in Table 5, there exists a marginal difference in the scores of Skill and Will components between male and female students. It is found that the female students scored $3.322=0.373$; for Skill and 3.391 for Will. However, the score was high for Self-regulation for female which is 3.522) $\left.=6.580 ; p<0.012 ; \eta^{2}=.063\right)$. The male students on the other hand, scored higher in the Skill component (3.622) but lower in both Will and Self-regulation (2.591 and 2.721, respectively). This concurs with Downing et al.'s (2008) study, which reported that female students yielded more positive attitudes and more sophisticated use of self-regulation strategies in their learning. Similarly, Ghazvini and Khajehpour (2011) also found that there were gender differences in the learning strategic domains with female students showing extensive internal locus of control, using attitude, motivation, time management, anxiety, and self-testing strategies, while male students used more strategies on concentration, information processing and selecting main ideas strategies. All of these findings imply that female students had better control than their male counterparts when dealing with motivation, emotion and management of a person's own cognition, behaviour and emotion. Male students on the other hand, were better in the aspects of knowledge and application of use.

\section{Conclusion}

The present study has indicated that students basically use all the strategies in their online learning. Although the findings show marginal differences between the subscales, the results can be beneficial in determining the students' level of use of the strategic learning 
components. The scores can inform instructors or institutions on providing academic resources or any specific intervention programme that can be organised to ameliorate students' academic performance. The difference in the use of strategic components between the genders also suggests that any intervention programme should not make the assumption that strategy use is the same for male and female students.

This study has presented general findings of the study and learning strategies of a general population of English language learners in online learning. Further research is needed to establish whether it is feasible to consider other mediating variables that can benefit the students in a long term. This is because, unlike traditional classroom where regular class meetings and instructor monitoring support students' learning and study skills, students in online learning do not have the benefit of such support. The students, themselves, are responsible for their own learning.

\section{References}

Alkhateeb, H. M., \& Nasser, R. (2014). Assessment of Learning and Study Strategies of University Students in Qatar Using an Arabic Translation of the Learning and Study Strategies Inventory. Psychological reports, 114(3), 947-965.

Bender, D. S., \& Garner, J. K. (2010). Using the LASSI to Predict First Year College Achievement:Is a Gender-specific Approach Necessary? Paper presented the Annual Meeting of the American Educational Research Association Denver, Colorado, April 30May 4, 2010.

Clarke, T., \& Hermens, A. (2001). Corporate developments and strategic alliances in elearning. Education and Training, 43(4/5), 256-267.

Cohen, J. (1988). Statistical power analysis for the behavioral sciences (2nd ed.). Lawrence Erlbaum Associates.

Cohen, D. A., Weaver J. S., \& Yuan-Tao, L. (1996). The Impact of Strategies - Based instruction on Speaking a Foreign Language. Center for Advanced Research on Language Acquisition: University of Minnesota.

Downing, K., Chan, S., Downing, W., Kwong, T., \& Lam, T. (2008). Measuring gender differences in cognitive functioning. Multicultural Education \& Technology Journal, 2(1), pp. 4-18.

Fillmore, L. W. (1979). Individual differences in second language acquisition. In Charles J. Fillmore et al. (Eds.). Individual Differences in Language Ability and Language Behavior, pp. 203-228. New York: Academic Press.

Ghazvini, S. D., \& Khajehpour, M. (2011). Gender differences in factors affecting academic performance of high school students. Procedia - Social and Behavioral Sciences. 15, 1040-1045.

Haghania, F., \& Sadeghizadeh, A. (2011). Intervention in the learning process of second year medical students. Journal of Research in Medical Sciences. 16(3),346-352.

Khalil, M. K., Williams, S. E., \& Hawkins, G. H. (2018). Learning and study strategies correlate with medical students' performance in anatomical sciences. Anatomical Science Education. 11(3),236-242.

Loong, T. E. (2012). Self-Regulated Learning between Low-, Average-, and High-Math Achievers among Pre-University International Students in Malaysia. European Journal of Social Sciences, 30(1-2),302. 
McConville, J., McAleer, R., and Hahne, A. (2017). Mindfulness Training for Health Profession Students-The Effect of Mindfulness Training on Psychological Well-Being, Learning and Clinical Performance of Health Professional Students: A Systematic Review of Randomized and Non-randomized Controlled Trials. EXPLORE. 13(1) 26-45.

Naiman, N., Frochlich, M., Stern, H. H., Todesco, A. (1978). The Good Language Learner. Ontario: The Ontario Institute for Studies in Education.

O'Malley, M. J., \& Chamot,A.U. (1990) Learning Strategies in Second Language Acquisition. Cambridge-London: Cambridge University Press.

Oxford, R. (1990). Styles, strategies, and aptitude. In Thomas S. Parry. \& Charles W. Stansfi eld (Eds.), Language Aptitude Reconsidered, pp. 67- 119. New Jersey: Prentice Hall Regents.

Oxford, R., \& Burry-Stock, J. A. (1995). Assessing the use of language learning strategies worldwide with the ESL/EFL version of the Strategy Inventory for Language Learning (SILL). System, 23 (1), 1-23.

Politzer, R., \& McGroarty, M. (1985). An exploratory study of learning behaviors and their relationship to gains in linguistics and communicative competence. TESOL, 19(1), 103123.

Rubin, J. (1981). Study of cognitive processes in second language learning. Applied Linguistics, 2(2), 117-131.

Schutz, C. M., Dalton, L. B. S., Rodger E. T. (2013). Learning and Study Strategies Inventory subtests and factors as predictors of National Board of Chiropractic Examiners Part 1 examination performance. Journal of Chiropractic Education 27 (1): 5-10.

Sera, L., \& McPherson, M. L. (2019). Effect of a study skills course on student self-assessment of learning skills and strategies. Currents in Pharmacy Teaching and Learning, 11(7),664668.

Sternberg, R. J. (1983). Criteria for intellectual skills training. Educational Research, 12 (2), 626.

Weinstein, C. E., Schulte, A., \& Palmer, D. (1987). LASSI: Learning and Study Strategies Inventory. Clearwater, FL: H\&H Publishing.

Weinstein, C. E., Palmer, D. R., \& Acee, T. W. (2016). LASSI User's Manual: For Those Administering the Learning and Study Strategies Inventory (3rd ed.). Clearwater, FL: $\mathrm{H} \& \mathrm{H}$ Publishing.

Wenden, A. (1991). Learner Strategies for Learner Autonomy. New York: Prentice Hall.

West, C., Kurz, T., Smith, S., and Graham, L. (2016) 'Are study strategies related to medical licensing exam performance?', International Journal of Medical Education, 5, 199-204. 